\title{
Dentin hypersensitivity treatment of non-carious cervical lesions - a single-blind, split-mouth study
}

\section{Simone da Silva FREITAS(a) Lucas Lopes Araújo SOUSA(b) José Machado MOITA NETO(c) Regina Ferraz MENDES(d) Raimundo Rosendo PRADO JUNIOR ${ }^{(d)}$}

(a) Universidade Federal do Piauí - UFPI, School of Dentistry, Health Sciences Center,Teresina, PI, Brazil.

(b) Universidade Federal do Piauí - UFPI, School of Dentistry, Post-Graduate Program in Dentistry, Teresina, PI, Brazil.

(c) Universidade Federal do Piauí - UFPI, Natural Science Center, Chemistry Department, Teresina, PI, Brazil.

(d) Universidade Federal do Piauí - UFPI, Health Sciences Center, Department of Restorative Dentistry, Teresina, PI, Brazil.

Declaration of Interests: The authors certify that they have no commercial or associative interest that represents a conflict of interest in connection with the manuscript.

\section{Corresponding Author:}

Raimundo Rosendo Prado Junior

E-mail: rosendo_prado@ig.com.br

DOI: $10.1590 / 1807-3107 B O R-2015 . v o l 29.0045$

Submitted: Jul 05, 2014

Accepted for publication: Dec 01, 2014

Last revision: Feb 03, 2015

\begin{abstract}
This study aims to compare the in vivo effect of a desensitizing therapy associated with a restorative technique for the treatment of cervical dentin hypersensitivity $(\mathrm{CDH})$ in non-carious lesions. The sample consisted of 68 teeth with moderate or severe dentin hypersensitivity in 17 individuals (one tooth per quadrant). The sensitivity levels of the teeth were scored, and the teeth were randomly distributed into four groups: T1 - desensitizing gel applied once per week until remission of pain; T2 - desensitizing gel applied once per week followed immediately by restoration with resin composite (Filtek Z250, 3M Espe); T3 - desensitizing gel once per week until remission of pain and then restoration with resin composite; and T4 - restoration with resin composite. Dentin hypersensitivity was assessed at 0, 7, 30, 90 and 180 days. The Kruskal-Wallis, Wilcoxon and Mann-Whitney $(p<0.05)$ tests were used to compare the treatments. The mean baseline $\mathrm{CDH}$ scores were T1 - 2.41, T2 - 2.41, T3 - 2.47, and T4 - $2.70(p>0.05)$. At seven and 180 days, the mean $\mathrm{CDH}$ scores were as follows: T1 - 1.47/0.65, T2 - 1.35/0.71, T3 - 0.71/0.53, and T4 - 1.12/0.59, all of which were significantly lower $(p<0.001)$ than the baseline scores. The scores at 30, 90 and 180 days were not significantly different when compared to the score of the previous period. At 180 days, $\mathrm{CDH}$ scores were similar among groups $(p>0.05)$. Teeth with moderate or severe hypersensitivity that required a filling responded similarly regardless of whether the desensitizing procedure was carried out prior to the filling.
\end{abstract}

Keywords: Tooth Wear; Dentin Sensitivity; Dental Materials.

\section{Introduction}

Cervical dentin hypersensitivity $(\mathrm{CDH})$ may be a result of gingival recession or abfraction, erosion and abrasion that lead to the characteristic loss of dental tissue and dentin exposure. ${ }^{1} \mathrm{CDH}$ is characterized by an acute and short-term pain, which can be triggered by the touch of an instrument, brush bristles, and cold or sweet food and drinks. ${ }^{2}$

The population prevalence of $\mathrm{CDH}$ ranges from $10 \%$ to $20 \%$ at age 40 , and it affects mainly canines and premolars. ${ }^{1,3}$ To date, no method has been developed to resolve $\mathrm{CDH}$ satisfactorily, and recurrences are common. ${ }^{4}$ Patients with $\mathrm{CDH}$ must be thoroughly evaluated for the diagnosis and control of etiological factors, because the treatment must achieve rapid and permanent pain relief. ${ }^{4,5}$ 
Despite numerous studies and available commercial products, $\mathrm{CDH}$ treatment still lacks a standard protocol to address patient discomfort. ${ }^{6}$ Ideally, the design of $\mathrm{CDH}$ studies should include the severe cases, otherwise, the conclusions may be limited. ${ }^{7}$ However, few studies have included such cases.

Thus, the aim of this study was to compare different types of therapeutic approaches (the use of a desensitizing agent associated or not with a restorative technique) to treat non-carious cervical lesions (NCCL) with moderate or severe $\mathrm{CDH}$. The hypothesis was that the tested therapeutic approaches would affect $\mathrm{CDH}$ differently.

\section{Methodology}

This study was carried out in Teresina, Brazil, at the Dental Clinic of the Universidade Federal do Piaui - UFPI after approval by the university's ethics committee (CAAE No. 0324.0.045.000-10) and the Brazilian Clinical Testing Registration - ReBEC (UTNREQ385UTN: U111-1125-7425). The participants gave signed consent for the study.

\section{Sample Selection and Power}

Three hundred and thirty-one patients sought treatment during the study period and were considered eligible. $\mathrm{CDH}$ prevalence was $17.8 \%$ (59 individuals) and 17 met the inclusion criteria. Individuals were not included if they had fewer than 20 teeth, had undergone periodontal scaling, had received desensitizing treatment or tooth whitening in the previous six months, had active bruxism, had systemic diseases, were drug users or pregnant women.

Teeth were not included if they had incipient NCCL, lacked the antagonistic teeth, had been previously restored, had questionable pulp vitality or were not eligible for rubber dam isolation.

The sample consisted of 8 females and 9 males between 29 and 57 years old (mean age 44.4 \pm 8.5 ). Each individual had four teeth $(\mathrm{N}=68$ teeth) with NCCL and moderate or severe CDH: one tooth did not require a filling, and three teeth did require a filling. The power analysis of the sample, which was carried out after the calculation of means and standard deviations of the $\mathrm{CDH}$ score using the software G*Power 3.1.9.2, ${ }^{8}$ was higher than $97 \%$ in all cases. The power of the sample between $\mathrm{T} 1$ and T3 for seven days was $69 \%$.

\section{Clinical Examinations and Interventions}

Anamnesis, visual and tactile clinical examination of teeth were carried out. Afterwards, the CDH severity of each tooth was recorded as follows: $0=$ no discomfort, 1 = mild, 2 = moderate, and $3=$ severe. ${ }^{5,9}$ Only teeth with CDH scores of 2 or 3 were included. Each tooth received a clinical probing (tactile stimulus) and air blast (thermal-evaporative stimulus). Air blast was applied with an air syringe for $1 \mathrm{~s}$ at a distance of $1 \mathrm{~cm} .70$ The Tooth Wear Index (TWI) ${ }^{11}$ was used to score the lesions' depth from 1 to 4 (Table 1). The depth was measured by placing a periodontal probe perpendicular to the tooth's long axis at the center of the lesion. Those with score 3 or 4 required a filling.

The operator was calibrated for the clinical interventions by attending presentations on how the treatments should be carried out and how to use the restorative materials. Any questions regarding the treatment protocol were clarified during the presentation.

In each patient, each tooth randomly received one type of treatment. A list of selected teeth was prepared for each patient, and they were arranged in a sequence according to a randomized approach. Then, a list of the treatments was randomly paired with the teeth.

The patient was not informed of the treatment for each tooth, and the clinical procedures were performed so that the patient could not distinguish among them, except for treatment 1.

The four treatments were:

- Treatment 1 (T1): Desensibilize KF 2\% desensitizing gel (Dentscare Ltda., Joinville, Brazil), with active ingredients $5 \%$ potassium nitrate and $2 \%$ sodium

Table 1. The tooth wear index (TWI).

\begin{tabular}{lc}
\hline TWI & Dental Wear \\
\hline 0 & No alteration of contour \\
1 & Minimal loss of contour \\
2 & Less than $1 \mathrm{~mm}$ deep \\
3 & Between 1 and $2 \mathrm{~mm}$ deep \\
4 & More than 2 mm deep, pulp exposure or exposure of \\
& secondary dentin \\
\hline
\end{tabular}


fluoride, was applied once per week according to the manufacturer's recommendations until complete remission of pain. Teeth were not restored in this group;

- Treatment 2 (T2): desensitizing gel was applied once, followed immediately by a restoration with Filtek Z250 resin composite and Adper Single Bond 2 adhesive (both from 3M Espe, Saint Paul, USA) following the manufacturers' recommendations;

- Treatment 3 (T3): desensitizing gel was applied once per week until complete remission of pain and a subsequent restoration with Filtek Z250 resin composite and Adper Single Bond 2 adhesive;

- Treatment 4 (T4): only restoration was performed with Filtek Z250 resin composite and Adper Single Bond 2 adhesive.

Resin increments no thicker than $2 \mathrm{~mm}$ were applied and photoactivated using an LED-type device (Ultraled-Dabi Atlante, Ribeirão Preto, Brazil) with frequency $50 / 60 \mathrm{~Hz}$ and minimum power $500 \mathrm{~mW} / \mathrm{cm}^{2}$.

The main outcome of the study was the patient's discomfort or pain relief - a patient-reported outcome (PRO-type). ${ }^{12}$

\section{Clinical Assessments}

Clinical assessments were conducted by a calibrated examiner, other than the operator, at baseline and at intervals of 7,30, 90 and 180 days after the treatments were performed. To assess the $\mathrm{CDH}$ intensity, an air blast was used.,13

The calibration was carried out at the Universidade Federal do Piauí - UFPI using a dental mannequin, an air-water syringe and an explorer. The duration of the calibration process (training, adjustments and calibration exercises) was approximately $16 \mathrm{~h}$, during which 10 patients with $\mathrm{CDH}$ were examined and their $\mathrm{CDH}$ scores were measured. The intraexaminer weighted kappa value was calculated by using the baseline values for $\mathrm{CDH}$ and by reexamining the patients seven days later. The kappa value was determined to be 0.76 .

For the clinical assessments, the examiner received a form with a list of the teeth whose $\mathrm{CDH}$ should be scored. He was blinded to the group to which each tooth belonged and the treatments that were being assessed. The order in which the teeth were evaluated was maintained during each observation period.

To process the data, SPSS 15 (SPSS Inc., Chicago, USA) for Windows was used. The results were analyzed using the Wilcoxon, Kruskal Wallis and Mann-Whitney tests $(p<0.05)$.

\section{Results}

The sample consisted of $8.8 \%$ maxillary incisors, $10.2 \%$ mandibular incisors, $7.35 \%$ maxillary canines, $35.3 \%$ maxillary premolars, $30.9 \%$ mandibular premolars, $34.4 \%$ maxillary molars and $3 \%$ mandibular molars. At baseline, the mean CDH scores of each group did not significantly differ from one another $(p>0.05)$ (Table 2). The recall rates were $100 \%$ for treatments 1,2 and 4 . For treatment 3 , two patients (12\%) missed the final assessment.

The mean $\mathrm{CDH}$ scores of groups and observation periods were compared using the Kruskal-Wallis test. A statistically significant difference between the treatments $(p<0.001)$ was found. At 7 days, there was a statistically significant difference between all treatments and the baseline: T1 $(p=0.001), \mathrm{T} 2(p=0.001)$, T3 $(p<0.001)$ and T4 $(p<0.001)$ (Table 2$)$. Furthermore, there was a statistically significant difference for T1 $(p=0.006), \mathrm{T} 2(p=0.04)$, and T4 $(p=0.023)$ when the mean $\mathrm{CDH}$ score at 180 days was compared with that at 7 days.

At seven days, there was a statistically significant percent reduction of the CDH scores for all groups $(p<0.05)$ (Table 2). No subsequent reduction was observed ( $p=0.221$ at 30 days; $p=0.825$ at 90 days; and $p=0.683$ at 180 days).

At 7 days, there was no significant difference in the mean $\mathrm{CDH}$ scores of T2, T3 and T4; furthermore, there was no significant difference among $\mathrm{T} 1, \mathrm{~T} 2$ and T4. However, the mean CDH score of T3 was lower than that of $\mathrm{T} 1(p=0.009)$. At 180 days, no difference was observed among treatments $(p>0.05)$ (Table 2).

The mean $\mathrm{CDH}$ score at 7 days was subtracted from that of the baseline to calculate the $\mathrm{CDH}$ score variation. This variable represents the early effect of each therapy, theoretically eliminating the subjectivity of the pain interpretation. There was a significant difference between treatments $(p=0.024)$. T3 and $\mathrm{T} 4$ had higher $\mathrm{CDH}$ score variations compared to 
Table 2. Mean $\mathrm{CDH}$ scores at observation periods, according to treatment.

\begin{tabular}{lccc}
\hline \multirow{2}{*}{ Treatment } & \multicolumn{3}{c}{ Mean (S.D.) } \\
\cline { 2 - 4 } & Baseline & 7 days & 180 days \\
\hline T1 & $2.41(0.5)^{a}$ & $1.47(0.8)^{\mathrm{b}}$ & $0.65(0.9)^{\mathrm{d}}$ \\
T2 & $2.41(0.5)^{\mathrm{a}}$ & $1.35(0.9)^{\mathrm{bc}}$ & $0.71(0.6)^{\mathrm{d}}$ \\
$\mathrm{T} 3$ & $2.47(0.5)^{\mathrm{a}}$ & $0.71(0.9)^{\mathrm{c}}$ & $0.53(0.9)^{\mathrm{d}}$ \\
$\mathrm{T} 4$ & $2.71(0.5)^{\mathrm{a}}$ & $1.12(0.6)^{\mathrm{bc}}$ & $0.59(0.5)^{\mathrm{d}}$ \\
\hline
\end{tabular}

The same letter indicates a lack of significant difference $(p<0.05)$.

$\mathrm{T} 1(p=0.01)$ and $\mathrm{T} 2(p=0.03)$. However, the mean $\mathrm{CDH}$ score variation after T4 was not statistically significant from that after T2 (Table 3).

The mean $\mathrm{CDH}$ score at 180 days of observation was subtracted from the baseline score to calculate the $\mathrm{CDH}$ score variation. This variable represents the late effect of each therapy. No significant $\mathrm{CDH}$ score variation was observed at 180 days $(p>0.05)$ (Table 3$)$.

\section{Discussion}

The aim of this study was to contribute to the methods of treatment of NCCL with $\mathrm{CDH}$. A pain scale was applied at the beginning and at the end of the experiment, so that pain intensity could be quantified and analyzed. The verbal scale used here has been adopted in previous studies to successfully measure $\mathrm{CDH} .3,5,7,9$ However, because pain is an individual experience, this study was limited by the psychological profile of participants and by the materials and techniques tested. Thus, patients who found it difficult to interpret the discomfort felt after treatments were performed were not included in the sample.

The use of desensitizing agents has been previously tested. ${ }^{13,14}$ Fluorides are one of the substances recommended for $\mathrm{CDH}$ treatment because they occlude the dentinal tubules by forming insoluble precipitates. Dentin permeability decreases, but the effect is short lived because fluoride interacts with calcium and calcium fluoride subsequently dissociates. ${ }^{14,15}$ However, potassium nitrate reduces nervous excitability. ${ }^{16}$ This effect is the mechanism of action currently accepted for the material tested in T1.

T1 had the highest mean sensitivity score at 7 days. Furthermore, T1 was able to gradually reduce sensitivity over time, leading to significant differences after 7 and 180 days (Table 2), despite
Table 3. Mean CDH scores variation (SD) at 7 and 180 days of observation when compared with baseline, according to treatment.

\begin{tabular}{lcc}
\hline Treatment & 7 days & 180 days \\
T1 & $0.94(0.89)^{a}$ & $1.76(0.97)^{a}$ \\
T2 & $1.05(0.96)^{\mathrm{ab}}$ & $1.70(0.91)^{a}$ \\
T3 & $1.76(0.97)^{\mathrm{c}}$ & $2.00(0.75)^{\mathrm{a}}$ \\
T4 & $1.58(0.87)^{\mathrm{bc}}$ & $2.11(0.600)^{\mathrm{a}}$ \\
\hline \multicolumn{2}{l}{ The same letter indicates a lack of significant difference. }
\end{tabular}

having the lowest mean sensitivity score variation (Table 3). Because its effect is cumulative, the gel must be reapplied at weekly intervals. The limitation of this technique is that it requires that patients abide by the professional recommendations in the interval between applications. Traumatic brushing technique or dietary habits are risk factors that should be diagnosed during anamnesis and modified during the therapy. T1's comparatively poor performance may have occurred because, once $\mathrm{CDH}$ remitted, therapy ceased, and there was likely a recurrence due to the difficult control of the etiological factors of $\mathrm{CDH}$. This factor was one limitation of this study that could have interfered with the final outcome. However, the operator kept close telephone contact with patients during the study to clarify any questions and to remind them of this drawback.

$\mathrm{T} 2$ had a relatively high mean $\mathrm{CDH}$ score and a similar variation to $\mathrm{T} 1$ at seven days (Tables 2 and 3 ). This technique was tested to simulate the potential for achieving a desensitizing effect and bonding technique in the same clinical session. Although there is no current clinical recommendation for such a procedure, the authors did not find any scientific evidence that it is contraindicated.

One single application of the gel may not have been sufficient to induce the formation of insoluble precipitates in the dentinal tubules. Furthermore, phosphoric acid etching increases dentin permeability. The latter may have been predominant because the two procedures occurred in the same clinical session. Dentin that is devoid of a smear layer is highly sensitive because products and stimuli are easily disseminated to the pulp., ${ }^{2,14,16}$ Furthermore, an incompatibility between the gel and the adhesive 
system would have resulted in a poor resinous infiltration and inadequate $\mathrm{CDH}$ control.

T3 and T4 had the lowest mean CDH score (Table 2) and the highest mean score variation (Table 3 ) at seven days of observation, respectively, which suggests that the synergistic effect between the desensitizing gel and subsequent filling with resin composite (T3) has the same effect as a filling with only a resin composite (T4). However, at least five consecutive weekly applications of the desensitizing gel were necessary for a $\mathrm{CDH}$ reduction to a mild or absent level. In the case of T4, the effect was significantly better at the end of the first observation period (7 days). Furthermore, the mean number of sessions required for T3 to achieve such a result was the same $(p>0.05)$ as for T1 (data not shown).

The choice of the desensitizing agent is important when the NCCL will subsequently be filled with a composite because the desensitizing agent that contain sodium and calcium fluoride may reduce the bond strength of adhesives. ${ }^{917}$ However, none of the fillings were lost, probably due to the use of a cavosurface bevel. ${ }^{18}$ The reduction in sensitivity may have been the result of the effect of potassium nitrate on nervous excitability. ${ }^{15}$ Furthermore, any agent that blocks the tubules reduces fluid flow, thereby reducing hypersensitivity. ${ }^{19}$ Thus, T3's results may reflect the effect of the gel on dentin permeability and nervous excitability, and the restorative technique could block the dentin fluid flow with the composite acting as a mechanical barrier against thermal stimuli. ${ }^{20}$ In the case of T4, the latter effect can be hypothesized.

Dentists frequently use bonding agents and composites to treat $\mathrm{CDH}$ due to their familiarity with composites. However, one study has shown that composites provided a longer lasting desensitizing effect when compared with home treatments. ${ }^{5} \mathrm{~A}$ different study found that dentists who were asked about $\mathrm{CDH}$ treatment reported a low success rate for the method..$^{21}$ Movement of intratubular fluid can be prevented by using restorative resins and adhesive systems, and provide comfort to $\mathrm{CDH}$ patients. ${ }^{22}$

The results suggest that combining the two techniques (desensitizing and composite filling) had the same effect as performing an immediate composite restoration, which is recommended when there is a substantial loss of tooth structure and teeth do not respond to other treatments. ${ }^{23}$ Restoring the tooth reduced the $\mathrm{CDH}$ quickly. Therefore, the hypothesis of the study was rejected.

Although there is a general consensus that a flexible restorative material in the cervical area is important, finite element analysis has raised awareness about the role of elasticity. One argument is that the elastic modulus of restorative materials would have to be significantly lower than the current level $(1 \mathrm{GPa})$ to have a clinically significant impact on its performance. Furthermore, adhesion quality plays a role in the behavior of restorations under tensile stress. Therefore, as long as the adhesive technique is carefully performed, the type of composite used is not as important as the choice of a material that has demonstrated clinical evidence of success. ${ }^{18}$ Thus, a microhybrid composite resin was selected for this study, all the restorations were placed under rubber dam isolation and the manufacturers' instructions were strictly followed.

An important limitation of this study is that etiology of NCCL were not taken into consideration. However, the patients were clarified about the etiological factors in order to control such factors whenever possible. Other studies that take into account the different clinical situations involved could be designed to compare different techniques and operatory conditions or the use of desensitizing substances and restorative materials in an attempt to resolve $\mathrm{CDH}$.

The clinical relevance of this study lies in the fact that evidence is in favor of carrying out an immediate filling of teeth with considerable tooth wear and moderate to severe $\mathrm{CDH}$. Further knowledge about dentin permeability is needed to understand the dynamics of $\mathrm{CDH}$.

\section{Conclusion}

The results of this study demonstrate the following:

a. The response of the teeth with $\mathrm{CDH}$ was more pronounced after 7 days of observation but without significant improvement thereafter;

b. It is more efficient to restore a tooth with moderate to severe $\mathrm{CDH}$ as soon as possible rather than trying to desensitize it prior to the filling procedure. 


\section{References}

1. Orchardson R, Gangarosa LP, Holland GR, Pashley $\mathrm{DH}$, Trowbridge HO, Ashley FP, et al. Dentine hypersensitivity-into the 21st century. Arch Oral Biol. 1994;39(Suppl):113S-119S.

2. Mjör IA. Dentin permeability: the basis for understanding pulp reactions and adhesive technology. Braz Dent J. 2009;20(1):3-16.

3. Rees JS, Addy M. A cross-sectional study of dentine hypersensitivity. J Clin Periodontol. 2002 Nov;29(11):997-1003.

4. Dababneh RH, Khouri AT, Addy M. Dentine hypersensitivity: an enigma? A review of terminology, epidemiology, mechanisms, aetiology and management. Br Dent J. 1999 Dec;187(11):606-11

5. Miglani S, Aggarwal V, Ahuja B. Dentin hypersensitivity: recent trends in management. J Conserv Dent. 2010 Oct;13(4):218-24.

6. Porto IC, Andrade AK, Montes MA. Diagnosis and treatment of dentinal hypersensitivity. J Oral Sci. 2009 Sep;51(3):323-32.

7. Holland GR, Narhi MN, Addy M, Gangarosa L, Orchardson R. Guidelines for the design and conduct of clinical trials on dentine hypersensitivity. J Clin Periodontol. 1997 Nov;24(11):808-13.

8. Faul F, Erdfelder E, Lang AG, Buchner A. G*Power 3: a flexible statistical power analysis program for the social, behavioral, and biomedical sciences. Behav Res Methods. 2007 May;39(2):175-91.

9. Yu X, Liang B, Jin X, Fu B, Hannig M. Comparative in vivo study on the desensitizing efficacy of dentin desensitizers and one-bottle self-etching adhesives. Oper Dent. 2010 May-Jun;35(3):279-86.

10. Rees JS, Jin LJ, Lam S, Kudanowska I, Vowles R. The prevalence of dentine hypersensitivity in a hospital clinic population in Hong Kong. J Dent. 2003 Sep;31(7):453-61.

11. Smith BG, Knight JK. An index for measuring the wear of teeth. Br Dent J. 1984 Jun;156(12):435-38.

12. Acquadro C, Berzon R, Dubois D, Leidy NK, Marquis $P$, Revicki $\mathrm{D}$, et al. Incorporating the patient's perspective into drug development and communication: an ad hoc task force report of the patient-reported outcomes (PRO) harmonization group meeting at the food and drug administration, February 16, 2001. Value Health. 2003 Sep-Oct;6(5):522-31.

13. Kielbassa AM, Attin T, Hellwig E, Schade-Brittinger C. In vivo study on the effectiveness of a lacquer containing CAF2/ $\mathrm{NaF}$ in treating dentine hypersensitivity. Clin Oral Investig. 1997 Jun;1(2):95-9.

14. Aranha AC, Pimenta LA, Marchi GM. Clinical evaluation of desensitizing treatments for cervical dentin hypersensitivity. Braz Oral Res. 2009 Jul-Sep;23(3):333-9.

15. Oda M, Matos AB, Liberti EA. Morphology of dentin treated with desensitizing substances: scanning electron microscopy study. Rev Odontol Univ São Paulo. 1999 Oct-Dec;13(4):337-42. Portuguese.

16. Pashley DH. Dentin permeability, dentin sensitivity, and treatment through tubule occlusion. J Endod. 1986 Oct;12(10):465-74.

17. Külünk S, Saraç D, Külünk T, Karakaş O. The effects of different desensitizing agents on the shear bond strength of adhesive resin cement to dentin. J Esthet Restor Dent. 2011 Dec;23(6):380-7.

18. Pecie R, Krejci I, García-Godoy F, Bortolotto T. Noncarious cervical lesions (NCCL) - a clinical concept based on literature review. Part 2: restoration. Am J Dent. 2011 Jun;24(3):183-92.

19. Zaimoglu A, Aydin AK. An evaluation of smear layer with various desensitizing agents after tooth preparation. J Prosthet Dent. 1992 Sep;68(3):450-7.

20. Santiago SL, Franco EB, Mendonça JS, Lauris JR, Navarro MF. One-year clinical evaluation of tooth-colored materials in non-carious cervical lesions. J Appl Oral Sci. 2003 Sep;11(3):175-80.

21. Cunha-Cruz J, Wataha JC, Zhou L, Manning W, Trantow $\mathrm{M}$, Bettendorf MM, et al. Treating dentin hypersensitivity: therapeutic choices made by dentists of the northwest precedent network. J Am Dent Assoc. 2010 Sep;141(9):1097-105

22. Pashley DH, Pashley EL, Carvalho RM, Tay FR. The effects of dentin permeability on restorative dentistry. Dent Clin North Am. 2002 Apr;46(2):211-45, v-vi.

23. King PA. Adhesive techniques. Br DentJ.1999 Apr 10;186(7):321-6. 